Article

\title{
Optimizing Chemically Enhanced Primary Treatment Processes for Simultaneous Carbon Redirection and Phosphorus Removal
}

\author{
Tianchen Dong ${ }^{1}$, Wudneh Ayele Shewa ${ }^{1}$, Kyle Murray ${ }^{2}$ and Martha Dagnew ${ }^{1, *}$ \\ 1 Department of Civil and Environmental Engineering, Western University, 1151 Richmond Street, London, \\ ON N6A 3K7, Canada; tdong8@uwo.ca (T.D.); wshewa@uwo.ca (W.A.S.) \\ 2 City of London, 300 Dufferin Avenue, London, ON N6B 1Z2, Canada; kjmurray@london.ca \\ * Correspondence: mdagnew@uwo.ca; Tel.: +1-519-661-2111 (ext. 87427)
}

Received: 25 February 2019; Accepted: 13 March 2019; Published: 16 March 2019

check for updates

\begin{abstract}
There has been increased interest towards maximizing wastewater energy recovery by enhancing the carbon captured through the primary treatment process such as chemically enhanced primary treatment (CEPT). This research was conducted to optimize the CEPT performance in terms of redirection of carbon and nutrients in both bench- and full-scale operations. In order to improve the CEPT process, the performance of ferric chloride and seven types of polymers were evaluated through jar testing. The optimal coagulant $(15 \mathrm{mg} / \mathrm{L}$ ferric chloride) and flocculant $(0.5 \mathrm{mg} / \mathrm{L}$ poly aluminum chloride (PACl)) combination achieved total COD, soluble COD, total suspended solids (TSS), and total phosphorus (TP) removal efficiencies of 76, 58, 89, and 84, respectively, in a full-scale primary clarifier operation. In doing so the organic matter and phosphorus were concentrated in CEPT sludge, making them available for recovery. Furthermore, the relationship between influent characteristics and removal rates under varying operating conditions was investigated. It was found that soluble COD removal appeared to be season-dependent, and TSS removals were independent of influent TSS concentrations in all scenarios. The removal of tCOD, SCOD, and TP had a positive relationship with their corresponding concentrations when the polymer Alcomer ${ }^{\circledR} 120 \mathrm{~L}$ was used, whereas no correlation between removal and concentration was observed with PACl.
\end{abstract}

Keywords: chemically enhanced primary treatment; carbon redirection; polymer; municipal wastewater; optimization; phosphorus removal

\section{Introduction}

One of the most prominent and practical topics, concerning all facets of the wastewater industry, is the necessity for low-energy and sustainable technologies. Recent developments in wastewater treatment have also heightened the need for carbon redirection from primary treatment units to transfer more carbon to anaerobic digestion or incinerators for maximizing energy recovery and generation. One of the existing technologies being considered for carbon redirection is chemically enhanced primary treatment (CEPT) [1]. CEPT refers to the process whereby chemicals are added to primary influent to promote coagulation and/or flocculation in primary clarifiers, resulting in improved removals via precipitation of particulate/dissolved solids as well as the carbon and nutrients associated with those solids [2]. Historically, metal salts, such as ferric chloride and alum, were considered as coagulants to be added to primary influent to enhance the removal of phosphorus. CEPT with metal salts have been shown to improve phosphate removal rates from 75 to $95 \%$ [3]. Wang et al. [4] also showed that dosing alum can effectively remove $78 \%$ of phosphate through primary treatment. Therefore, the addition of metal salts has been demonstrated to have a significant impact on 
phosphorus removal performance for primary clarification when compared to a conventional clarifier, which typically only achieves removals of approximately $30 \%$. Further, the chemical addition causes the particulate matter to form larger flocs, increasing the settling rate and thus reducing the required residence time for primary treatment, which translates into the ability to treat higher wastewater flows in wet weather or overflow conditions without compromising primary treatment performance [4]. Odegaard [5] conducted research on the impact of polymer to supplement metal salt addition for a CEPT process. This research showed a promising increase in the floc settling rate allowing similar performance at higher surface overflow rates than when the metal salts were used alone. The results of bench-scale testing show that the total suspended solids (TSS) removal rate can be increased to around $90 \%$ by adding coagulant and flocculants [6-8]. Furthermore, the results of a survey of 100 wastewater treatment plants in the United States suggest that, based on a comparison of full-scale CEPT applications to conventional primary clarification under similar operating conditions, CEPT results in a 30\% increase in TSS removed through primary treatment [9].

Currently, many wastewater treatment plants are being upgraded for the purpose of resource recovery. As part of this process, both wastewater engineering practitioners and researchers are considering the role that the CEPT process can play. Compared with conventional primary treatment, CEPT shows superior efficiencies in removing suspended solids and phosphorus [10]. As organic carbon is a potential energy-rich component of wastewater, a key consideration for sustainable, energy self-sufficient wastewater treatment is the removal and management of the carbon in the influent wastewater. Therefore, the removal rate of total chemical oxygen demand (tCOD) and soluble chemical oxygen demand (sCOD) will be a more important parameter in the design and operation of CEPT. Furthermore, although there are some recent studies that discuss the potential of using CEPT in carbon redirection, there is a notable lack of research being undertaken that focuses on optimizing CEPT for simultaneous carbon and nutrient redirection by removing more tCOD, sCOD, and total phosphorus (TP).

If a large amount of carbon can be redirected by CEPT compared to traditional primary treatment, a larger portion of pollutants are concurrently removed via CEPT sludge rather than requiring removal through downstream biological or chemical treatment processes. Additionally, the pollutants concentrated in CEPT sludge, such as organic carbon, can be regarded as valuable resources to increase anaerobic digester gas production or promote autogenous combustion in sludge incineration. The other advantages of CEPT include a reduction of the footprint of primary settling processes, as it permits operation at high surface overflow rates, while also reducing the footprint and operating cost of subsequent biological treatment processes due to the decreased organic and nitrogen loadings contained in primary effluent. Despite these advantages, previous studies concerning CEPT have only focused on the selection of coagulants and flocculants for wet weather flow conditions and phosphorus removal $[2,11,12]$. Studies that holistically address the potential for optimization of CEPT technology for simultaneous carbon redirection, wet weather flow, and phosphorus removal are limited. Thus, the objectives of this study are to (1) investigate the effectiveness of several polymers with ranging characteristics on simultaneous carbon and nutrient removal using jar testing, (2) monitor and characterize full-scale long-term CEPT performance under optimal and suboptimal polymer dosing operations, and (3) evaluate the influence of influent characteristics on removal rates under varying operating conditions.

\section{Materials and Methods}

This study was conducted using bench-scale units to address the above objectives prior to evaluation at full-scale. The bench-scale study was conducted systematically to identify the best coagulant/polymer combination for achieving simultaneous carbon redirection and $\mathrm{P}$ removal. The study evaluated the effectiveness of seven different types of polymers in combination with ferric chloride by assessing the removals of $\mathrm{tCOD}$, SCOD, TP, and TSS. After the optimal combination was identified, it was further implemented on a full-scale primary clarifier in a side-by-side comparative 
evaluation using a similar full-scale conventional clarifier as a control. The primary influent and effluent from both full-scale clarifiers were characterized, and the long-term performance of each clarifier, as well as the impact of the primary influent characteristics on their performance, was evaluated.

\subsection{Full-Scale Site Layout and Sampling}

Full-scale tests were conducted at the Vauxhall Pollution Control Plant (PCP) (London, ON, Canada). The plant has two sections, designated as Sections 1 and 2, treating two-thirds and one-third of the total flow, respectively (Figure 1). According to the 2016 annual report, the average daily flow of the Vauxhall PCP is $13,500 \mathrm{~m}^{3} /$ day [13]. The plant makes use of ferric chloride for phosphorus removal and occasionally uses Alcomer ${ }^{\circledR} 120 \mathrm{~L}$ polymer (hereafter called Alcomer) to enhance the plant's performance during wet weather flow conditions. The CEPT optimization experiment was conducted on the section designated as Section 2, and Section 1 was monitored as a control clarifier (Figure 1). During the test period, the flow going to each section was manipulated to maintain similar surface overflow rate and detention time between the test and the control clarifiers (Table 1). Ferric chloride addition for phosphorus removal was resumed for Section 1 influent (herein referred to as the control clarifier), while a selected polymer in combination with ferric chloride was added to the Section 2 influent (herein referred as the test clarifier) for simultaneous carbon redirection and phosphorus removal. The influent and effluent of the primary clarifiers of both sections (Sections 1 and 2) were collected twice per week for wastewater quality analysis, which included tCOD, sCOD, total phosphorus (TP), and total suspended solids (TSS). The operating parameters and characteristics of the raw wastewater are shown in Table 1.

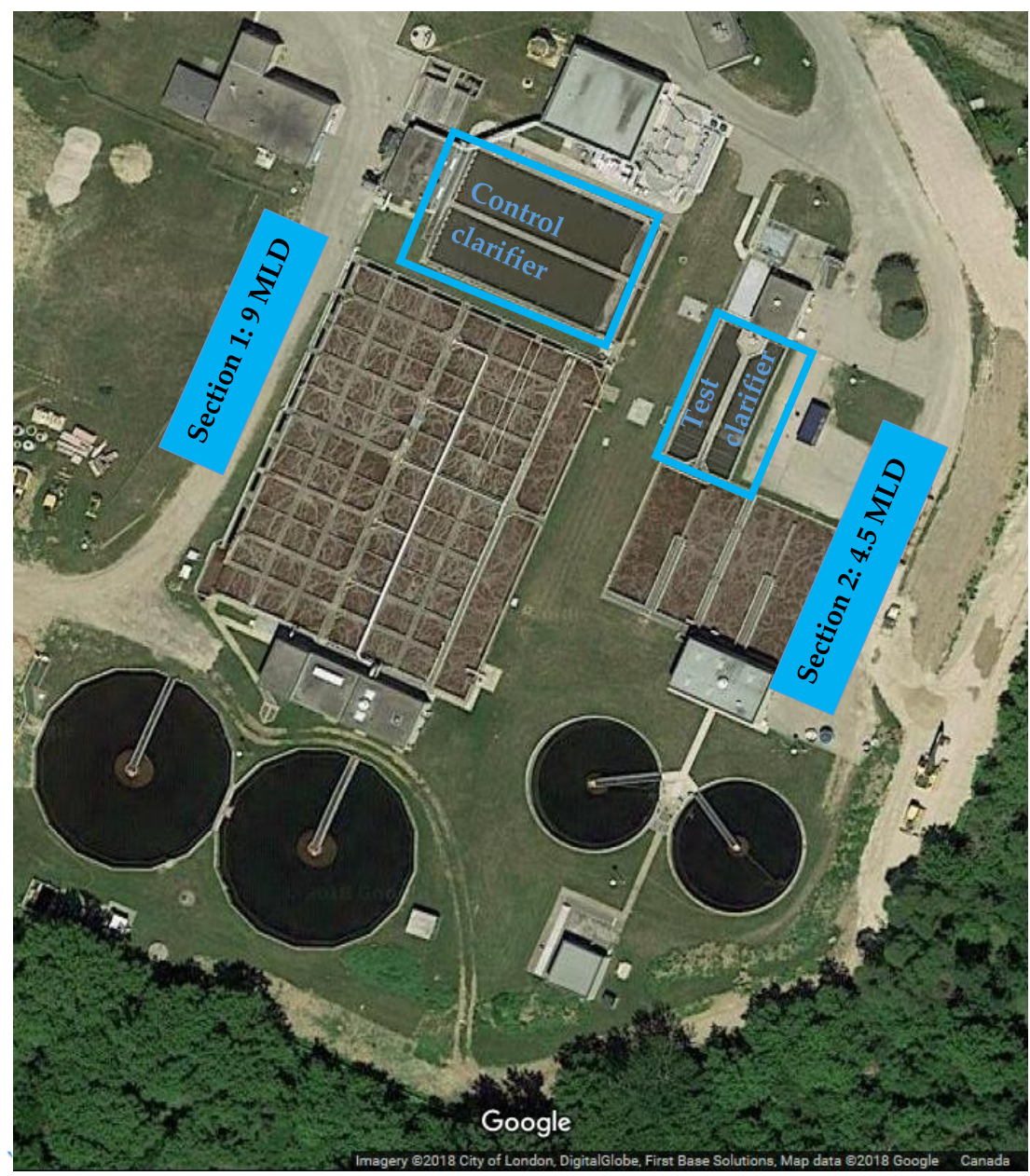

Figure 1. Layout of the Vauxhall Pollution Control Plant (PCP). 
Table 1. Clarifier operating parameters and wastewater characteristics.

\begin{tabular}{ccc}
\hline Operating Parameters & Control Clarifier & Test Clarifier \\
\hline Flow (MLD) & 9 & 4.5 \\
Detention time $(\mathrm{h})$ & 1.7 & 1.8 \\
Surface overflow rate & 32 & 30 \\
$\left(\mathrm{~m}^{3} / \mathrm{m}^{2} /\right.$ day $)$ & $354^{*}$ \\
TSS, mg/L & $228^{*}$ \\
BOD, mg/L & $6.3^{*}$ \\
TP, mg/L & \\
$*$ 24-h composite samples, average year.
\end{tabular}

\subsection{Bench-Scale Jar Testing and Polymer Selection}

The jar test experiments were performed using Phipps and Bird PB-900 six-paddle flocculation stirrer and the contents of the jars were mixed simultaneously. One liter of raw wastewater was placed into each of the jars and a fixed dosage of ferric chloride $(15 \mathrm{mg} / \mathrm{L})$ was added to each jar. The ferric chloride dosing rate was adopted from the plant and was consistent with the optimal rate being applied at the full-scale plant for TP removal. After the addition of ferric chloride, the wastewater was briefly stirred at $100 \mathrm{rpm}$ for $1 \mathrm{~min}$, and increasing dosages of polymer solution $(0.25-2 \mathrm{mg} / \mathrm{L})$ were added to each jar as quickly as possible in succession, and then slowly stirred at $20 \mathrm{rpm}$ for another $2 \mathrm{~min}$. The wastewater mixture was then allowed to settle for $30 \mathrm{~min}$, and a sample of supernatant was then withdrawn for analysis.

As part of the jar testing methodology, special emphasis was placed on the method of coagulant and flocculant addition to mimic the dosing conditions typically found at full-scale wastewater treatment facilities $[14,15]$. In actual wastewater treatment plants, standard design practice is to inject coagulant at a location where there is a high degree of turbulence in order to stimulate the process of coagulation. Because of the negative impact of rapid mixing on the flocculation process, causing a break-up of already formed flocs, flocculants are typically added in a more quiescent location. Concomitant to this, the coagulant was added during rapid mixing followed by flocculant addition during slow mixing.

A total of 126 tests were performed using seven different polymers, each applied at concentrations of $0.25,0.5,0.75,1,1.5$, and $2 \mathrm{mg} / \mathrm{L}$ and conducted in triplicate. Prior to the test, stock solutions of ferric chloride and the seven different polymers were prepared and stored at $21^{\circ} \mathrm{C}$ in sealed plastic bottles. Table 2 provides a summary of the polymers used for this study. The polymers were selected based on their wide range of characteristics and their potential impact on carbon redirection.

Table 2. Comparison of different polymers.

\begin{tabular}{ccc}
\hline Polymer Name & Type & Composition \\
\hline Polyacrylamide & Nonionic & $\left(\mathrm{C}_{3} \mathrm{H}_{5} \mathrm{NO}\right) \mathrm{n}$ \\
Polyacrylamide & Anionic & $\left(\mathrm{C}_{3} \mathrm{H}_{5} \mathrm{NO}\right) \mathrm{n}$ \\
Polyacrylamide & Cationic & $\left(\mathrm{C}_{3} \mathrm{H}_{5} \mathrm{NO}\right) \mathrm{n}$ \\
Poly aluminum chloride & - & $\left(\mathrm{Al}_{2}(\mathrm{OH})_{3} \mathrm{Cl}_{3}\right) \mathrm{n}$ \\
BASF 8848FS (B1) & Cationic & Unknown, proprietary \\
BASF 8858FS (B2) & Cationic & Unknown, proprietary \\
Alcomer & Anionic & Anionic, acrylamide-based copolymer \\
\hline
\end{tabular}

\subsection{Wet Chemistry and Statistical Analysis}

The wet chemistry analysis including total and soluble COD and TP was performed according to $\mathrm{HACH}$ methods 8000 and 10127, respectively (HACH, Loveland, CO, USA). TSS values were measured as per the standard methods [16]. All analyses of field samples were carried out within $24 \mathrm{~h}$ after their collection to minimize any changes in wastewater characteristics. Samples collected during jar testing were analyzed immediately after collection. The assessment of normality of the data and mean 
comparison was made using the Anderson-Darling Test and t-test, respectively [17]. MINITAB 18 (www.minitab.com, Minitab Inc., State College, PA, USA), a statistical software program, was used to determine the skewness, kurtosis, Anderson-Darling $p$-values, and t critical values.

\section{Results and Discussion}

\subsection{An Evaluation of Polymer Type on Simultaneous Carbon Redirection and TP Removal}

The carbon and nutrients removal efficiencies of the seven polymers described in Table 2 were investigated for the purpose of selecting an optimal polymer type and its corresponding dosage. The evaluation was conducted using jar testing with a fixed coagulant (ferric chloride) dose of $15 \mathrm{mg} / \mathrm{L}$ and varying doses of polymers. The details of the comparison are described in the subsequent sections.

Figure 2a-d illustrate the performance of different types and concentrations of polymers in terms of tCOD, sCOD, TSS, and TP removals. Overall, the tCOD removal ranged from $22 \pm 2$ to $94 \pm 2 \%$ (Figure 2a). The results indicated an optimal polymer dose of $<1 \mathrm{mg} / \mathrm{L}$ with corresponding tCOD removals ranging from $68 \pm 0.8$ to $94 \pm 2 \%$. The highest removal achieved $(94 \pm 2 \%)$ was demonstrated when applying poly aluminum chloride $(\mathrm{PACl})$ at a dose of $0.5 \mathrm{mg} / \mathrm{L}$ : the removal rate was found to be $20-68 \%$ higher than the removal efficiencies of the other six polymers (Figure 2a). The best tCOD removal rate for nonionic PAM, cationic B1, cationic PAM, and anionic PAM were $71 \pm 0.8,68 \pm 0.8$, $74 \pm 2.1$, and $68 \pm 0.7 \%$, respectively. This demonstrates that the charge associated with the PAM had no substantial impact on the tCOD removal. For the Alcomer and B2, the highest removal rates were $43 \pm 0.7$ and $26 \pm 0.7 \%$, which demonstrate that the cationic polyelectrolyte and high-molecular-weight polymer (Alcomer) achieve a poor tCOD removal efficiency. Previous studies have demonstrated that $\mathrm{PACl}$, even when used alone as a coagulant, can achieve good removals $[8,10,18]$. These studies have reported tCOD removal rates ranging from 40 to $80 \%$ at dosages of $\mathrm{PACl}$ ranging from 20 to $2000 \mathrm{mg} / \mathrm{L}$. The results observed during the jar testing completed under the current study indicate that, if $\mathrm{PACl}$ can be used with ferric chloride, not only are tCOD removal rates greatly enhanced, but that the concentration of $\mathrm{PACl}$ can be decreased to a dose as low as $0.5 \mathrm{mg} / \mathrm{L}$ while still achieving high removals. This suggests that $\mathrm{PACl}$ addition is a cost-effective method to improve the primary clarifier performance relative to tCOD removal.

A second parameter that was investigated in relation to carbon redirection is $\mathrm{sCOD}$. Figure $2 \mathrm{~b}$ shows the percent SCOD removals upon the addition of various polymers. The results show lower sCOD removals ranging from $2 \pm 0.7$ to $30 \pm 3.1 \%$ for all polymers, with the exception of the nonionic PAM polymer, which showed a 70\% removal at a dosing rate of $0.5 \mathrm{mg} / \mathrm{L}$. The cationic polymer $\mathrm{B} 2$ and Alcomer showed the lowest removals. These results are noted to be consistent with tCOD performance. The sCOD removal rate could either be the result of the removal of the true soluble fraction or the fraction of colloidal COD present after filtering the sample using a 0.45 -micron filter. In order for sCOD to be removed, it would first need to be converted to insoluble forms, either by complexation and formation of insoluble precipitates, by adsorption, or by a combination of these processes [19]. From Figure $2 b$, it can be seen that the nonionic polymer is the only polymer that achieved a notable increase in removal when compared to the remaining six polymers tested, which are either positively or negatively charged. This phenomenon may be explained by the fact that soluble COD is not preferably adsorbed on the floc which is formed during the coagulation process with charged polymers, whereas nonionic PAM, which does not contain a charge, assists in the conversion of soluble COD to particulate forms, and this enhances removal. The results of the current study, which demonstrates lower relative sCOD removals achieved by the other six polymers, are in agreement with similar studies conducted by Haydar and Aziz [20], which demonstrated that only a small portion (ranging from 7 to $28 \%$ ) of sCOD can be removed by the adsorption of $\mathrm{sCOD}$ on $\mathrm{Al}(\mathrm{OH})_{3}$ floc during the process of coagulation. 


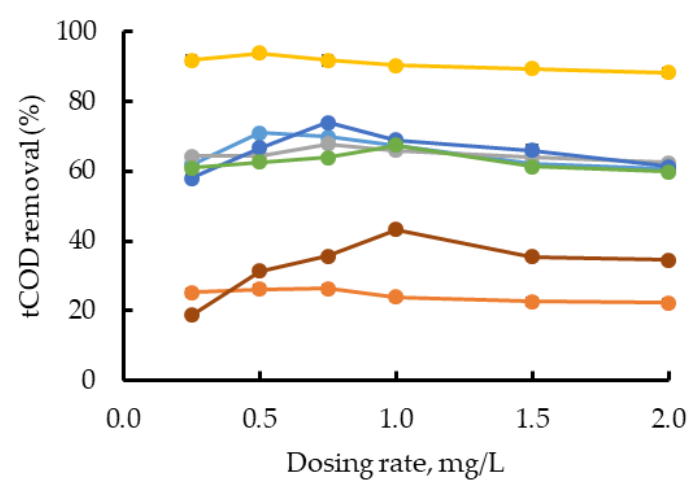

(a)

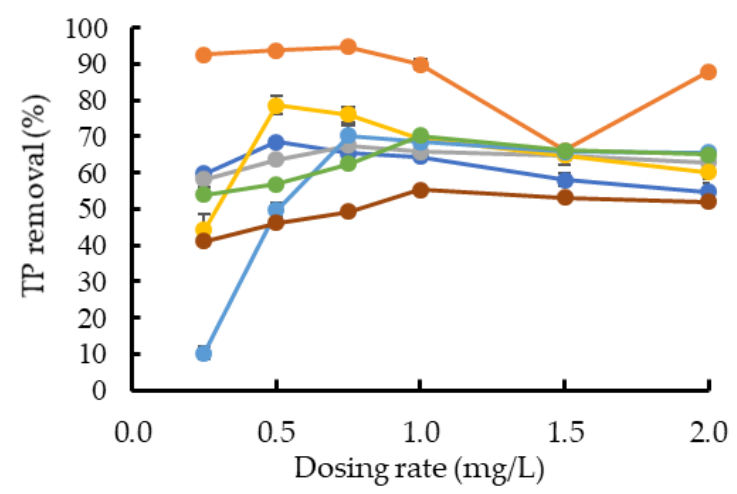

(c)

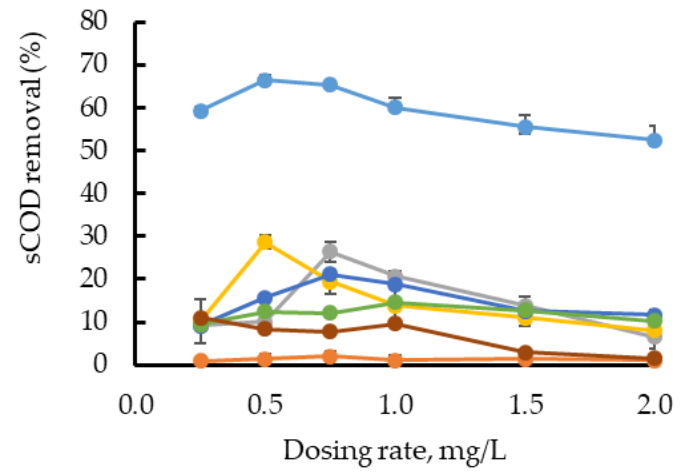

(b)

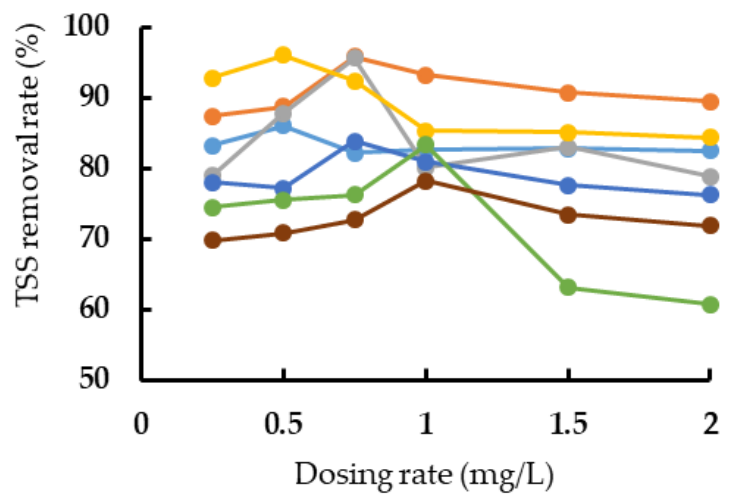

(d)

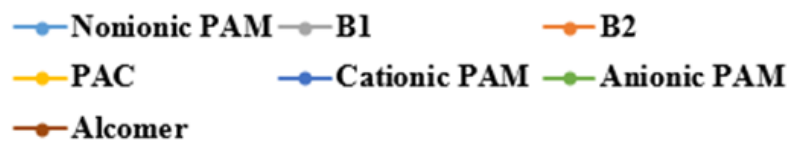

Figure 2. Percent removal by individual polymers with $15 \mathrm{mg} / \mathrm{L}$ ferric chloride (values are averages of triplicates): (a) tCOD, (b) sCOD, (c) TP, and (d) TSS.

Figure 2c shows the TP removal achieved though the dosing of ferric chloride $(15 \mathrm{mg} / \mathrm{L})$ coupled with various polymers. The cationic polymer, B2, was found to be the best polymer to be used with ferric chloride for removing TP based on an observed removal rate of $95 \pm 1.1 \%$ at a polymer dosage of $0.75 \mathrm{mg} / \mathrm{L}$. The TP removal efficiency of other cationic, anionic, or nonionic polymers is in the range from $50 \pm 2.4$ to $70 \pm 2.5 \%$, with the exception of $\mathrm{PACl}$, which removed $80 \pm 4.9 \%$ of TP. These results demonstrate that the charge of polymer is not the decisive factor. This can be concluded on the basis of equal removal rates from both anionic PAM (70.2 $\pm 2.1 \%)$ and cationic PAM (70.2 $\pm 5.4 \%)$. Most of the TP is removed by ferric and polymer ion co-precipitation [21,22]. However, B2 (cationic polyelectrolyte) displayed a much better performance for removing $\mathrm{TP}$, which demonstrates that the liquid grade cationic polyelectrolyte used is superior for TP removal to all varieties of PAM tested. Further research regarding the impact of the characteristics of B2, such as its molecular weight, charge density, and viscosity on its bridging and patch charge neutralization capability, need to be done to establish this argument.

Figure 2d graphically illustrates the observed TSS removals associated with various polymers added as coagulant aid. Typically, the capability of polymers to remove TSS is an indicator of their potential use for wet weather flow conditions. Interestingly, almost all combinations of ferric chloride and the various types and concentrations of polymers tested achieved removals that exceeded $70 \%$. This is in contrast to the results of tCOD, sCOD, and TP removal efficiencies. Three of the polymers, $\mathrm{PACl}, \mathrm{B} 1$, and B2, had higher ( $>90 \%$ ) and comparable TSS removal rates (Figure 2d). However, the dosage needed to achieve these removals with $\mathrm{PACl}(0.5 \mathrm{mg} / \mathrm{L})$ was found to be lower than the 
other two polymers $(0.75 \mathrm{mg} / \mathrm{L})$ (Figure $2 \mathrm{~d}$ ). Therefore, $\mathrm{PACl}$ was considered the best polymer from a performance and cost standpoint for the removal of TSS. The ability of $\mathrm{PACl}$ to achieve a high level of removal despite a lower dosage, compared to other polymers, may be explained by its polymeric form and higher molecular weight providing both charge neutralization and bridging ability. Molecular weight and intrinsic viscosity are the most important factors in the coagulation and flocculation process, owing to the size and bridging ability of the molecules for aggregation [23]. In addition, the ratio of the $\mathrm{Al}^{3+}$ and the positive charge are elevated, which effectively brings about its excellent capabilities of bridging and aggregating for flocculation [24].

\subsection{Selection of the Best Performing Polymer}

The summary of the results obtained from the jar test analysis is shown in Table 3. It is apparent from this table that selecting the best performing polymer is not straightforward because no single polymer provides the best observed removal efficiency for each of the parameters considered. Thus, a simplified comparison matrix introduced by Feo et al. [15] was used. In this process, an equal weight of 2 was assigned to COD, TSS, TP, and dosage, and the corresponding index for each polymer and its impact on each parameter was determined. Averages of the four weighted values were then compared (Table 4), and the polymer with the highest index was selected as the optimal polymer. The results, as shown in Table 4, indicate that PACl (average index $=1.916$ ) is the best polymer. Therefore, using $0.5 \mathrm{mg} / \mathrm{L} \mathrm{PACl}$ combined with $15 \mathrm{mg} / \mathrm{L}$ of ferric chloride can achieve removals as high as $94 \%$ of $\mathrm{tCOD}, 29 \%$ of sCOD, $79 \%$ of TP, and $96 \%$ of TSS through CEPT. Although the sCOD removal efficiency of $\mathrm{PACl}$ is not the highest compared to the nonionic PAM (Figure 3), it exhibits an outstanding performance in removing tCOD, TP, and TSS. In addition to better performance, the cost of PACl (200-350 USD/ton) was much lower than PAM (1000-1800 USD/ton), making it the most economic polymer.

Table 3. Comparison of different polymers.

\begin{tabular}{cccccc}
\hline \multirow{2}{*}{ Polymer Type } & \multirow{2}{*}{ Optimum Dosage $(\mathbf{m g} / \mathrm{L})$} & \multicolumn{4}{c}{ Removal Efficiency (\%) } \\
\cline { 3 - 6 } & & tCOD & sCOD & TP & TSS \\
\hline Nonionic PAM & 0.5 & 71 & 66 & 68 & 86 \\
Anionic PAM & 1 & 67 & 15 & 70 & 83 \\
Cationic PAM & 0.75 & 74 & 21 & 70 & 84 \\
PACL & 0.5 & 94 & 29 & 78 & 96 \\
B1 & 0.75 & 68 & 26 & 67 & 96 \\
B2 & 0.75 & 26 & 2 & 95 & 96 \\
Alcomer & 1 & 43 & 10 & 55 & 78 \\
\hline & Min $=0.5$ & Max $=94$ & Max $=66$ & Max $=95$ & Max $=96$ \\
\hline
\end{tabular}

Table 4. Alternative matrix of polymers using equilibrate weight distribution.

\begin{tabular}{|c|c|c|c|c|c|}
\hline \multirow[b]{2}{*}{ Polymer Type } & \multicolumn{4}{|c|}{ Criteria $^{1}$} & \multirow[b]{2}{*}{ Average Index } \\
\hline & $\begin{array}{l}\text { tCOD Removal } \\
\text { Index }^{2}\end{array}$ & $\begin{array}{l}\text { TP Removal } \\
\text { Index }^{2}\end{array}$ & $\begin{array}{l}\text { TSS Removal } \\
\text { Index }^{2}\end{array}$ & $\begin{array}{l}\text { Dosage } \\
\text { Index }^{3}\end{array}$ & \\
\hline $\mathrm{PACl}$ & 2.000 & 1.662 & 2.000 & 2.000 & 1.916 \\
\hline Nonionic PAM & 1.512 & 1.445 & 1.794 & 2.000 & 1.688 \\
\hline B1 & 1.446 & 1.426 & 1.992 & 1.333 & 1.549 \\
\hline Cationic PAM & 1.578 & 1.483 & 1.746 & 1.333 & 1.535 \\
\hline B2 & 0.560 & 2.000 & 1.996 & 1.333 & 1.472 \\
\hline Anionic PAM & 1.438 & 1.483 & 1.735 & 1.000 & 1.414 \\
\hline Alcomer & 0.922 & 1.170 & 1.629 & 1.000 & 1.180 \\
\hline
\end{tabular}

${ }^{1}$ Each criterion is attributed an equal weight of $2 ;{ }^{2}$ Index $=2 \times$ Removal (\%)/observed maximum removal (\%);

${ }^{3}$ Index $=2 \times$ Observed minimum dosage/optimum dosage; ${ }^{4}$ Average index is the average of the 4 weighted values for each alternative. 
(a)

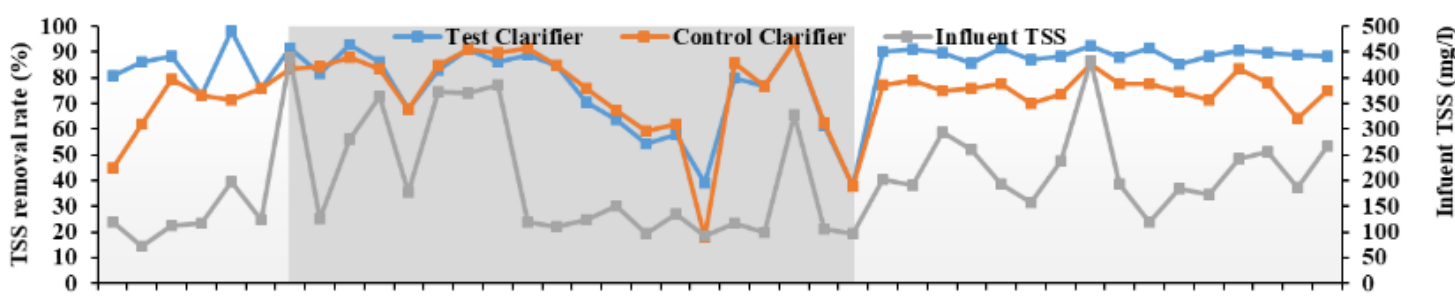

(b)

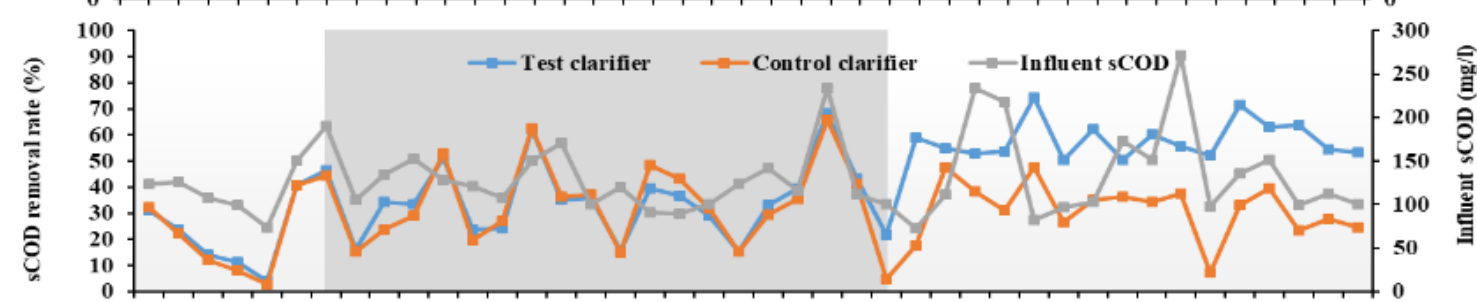

(c)
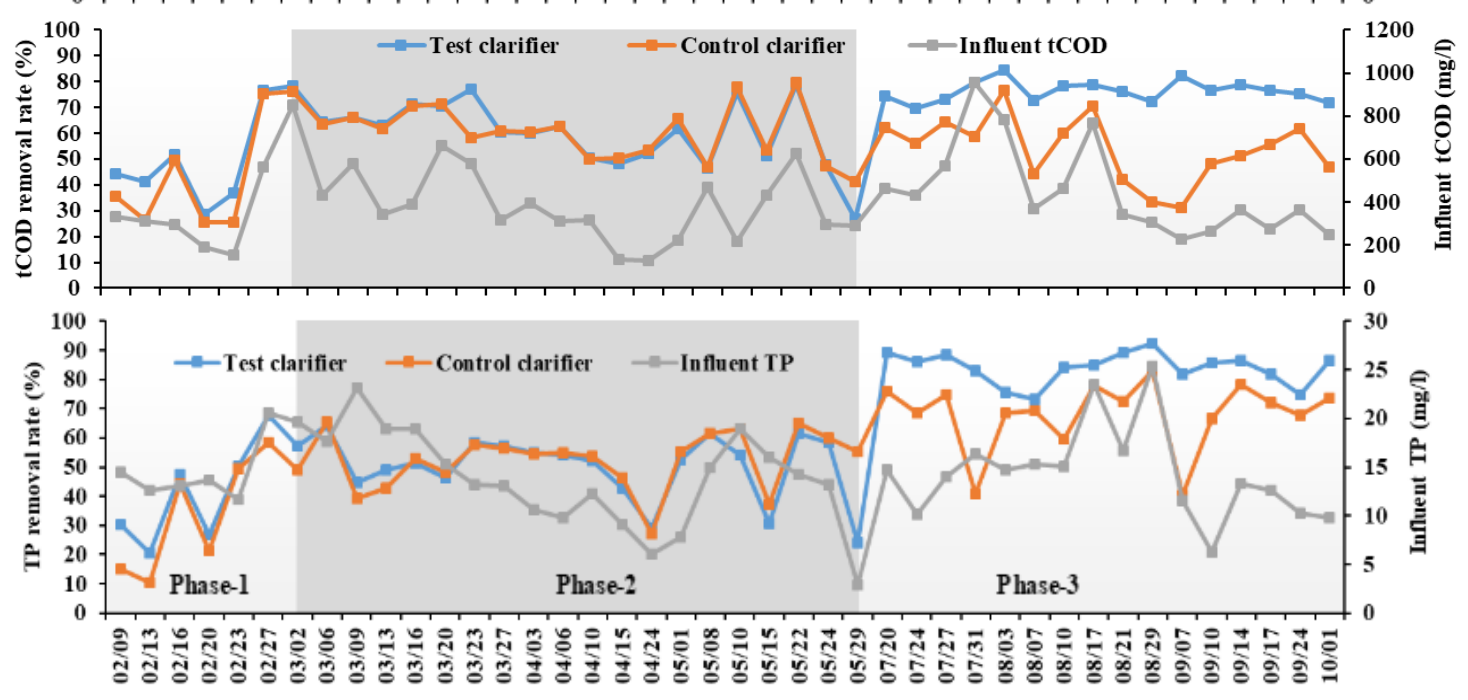

month/day

Figure 3. Removal efficiency profile: (a) TSS, (b) tCOD, (c) sCOD, and (d) TP removal. 


\subsection{Full-Scale Carbon Redirection, TP Removal and Wet Weather Flow Performance}

Full-scale carbon redirection, TP removal, and wet weather flow performance characterization were conducted at the Vauxhall PCP using both a test and control clarifier. During the study period, these clarifiers operated at a surface overflow rate of 30 and $32 \mathrm{~m}^{3} / \mathrm{m}^{2} /$ day, respectively. Prior to this experiment, the plant had been dosing $15 \mathrm{mg} / \mathrm{L}$ ferric chloride for phosphorus removal and had used Alcomer on an as-needed basis to enhance the plant's performance during wet weather flows. The full-scale test was conducted in three phases: (1) Phase 1: in addition to ferric chloride, Alcomer at $1 \mathrm{mg} / \mathrm{L}$ was added on a continuous basis to assess the effectiveness of the plant's existing wet weather flow for carbon redirection and TP removal; (2) Phase 2: the test and control clarifiers subjected to only ferric chloride dosing were compared; (3) Phase 3: test clarifier, which received a dose of ferric chloride followed by an optimized polymer ( $\mathrm{PACl})$, was compared with the control clarifier receiving only ferric chloride.

The TSS, tCOD, sCOD, and TP removal efficiency for both the test and control full scale primary clarifiers during Phase 1 are depicted in Figure 3a-d. The average TSS, tCOD, sCOD, and TP removal efficiencies for the control were $68 \pm 12,40 \pm 20,20 \pm 14$, and $33 \pm 20 \%$ and for the test clarifier with polymer addition were $84 \pm 9,47 \pm 16,21 \pm 13$, and $41 \pm 18 \%$, respectively. For most of the parameters, the test clarifier demonstrated marginal improvement except for TSS, where a substantial $(16 \%)$ improvement in removal was demonstrated. This confirms that the usage of Alcomer polymer during wet weather flow conditions could be used to enhance removals. However, it should be noted that the enhancement in TP removal was not comparable with other studies that reported higher removal rates of around $80 \%[10,11]$. It is theorized that the reason why the Alcomer does not achieve a higher performance improvement may be because of the polymer itself or the performance of the two primary clarifiers having an inherent difference requiring further data collection and statistical analysis. Thus, the addition of Alcomer to the test primary clarifier was stopped in order to compare the performance of the two primary clarifiers under similar conditions.

The shaded areas in Figure 3a-d represent the period when Alcomer was not added to the test primary clarifier (Phase 2). The two primary clarifiers exhibited similar performance; however, another observation to emerge from the data comparison between Phase 2 and Phase 1 was the increase in the primary clarifier removal rate of TSS, COD, SCOD, and TP during Phase 2. During this period, although polymer dosing was suspended, primary removals increased from an average of $68 \pm 12$, $40 \pm 20,20 \pm 14$, and $33 \pm 20 \%$ during Phase 1 to $74 \pm 19,74 \pm 10,34 \pm 16$, and $51 \pm 10 \%$ during Phase 2 for TSS, COD, sCOD, and TP, respectively. These increases may be explained due to the weather conditions during Phase 1 testing; several snow melt events occurred in February during which approximately $35 \mathrm{~mm}$ of rain was received. This resulted in elevated influent flows, which increased the operating surface overflow rate more than those during Phase 2. Operation under these conditions and the lower temperature (data shown in Figure S1) likely explains some of the reduced removals observed during Phase 1.

In summary, the results from Phase 2 demonstrate that the treatment efficiency of the control and test clarifiers when operated under identical condition were similar. Subsequently, the addition of polymer was reinitiated, this time using the selected optimal polymer $(\mathrm{PACl})$ in the test clarifier for a period of over 2 months. Phase 3 results demonstrate a clear improvement in the removal rates achieved for the parameters investigated (Figure 3a-d).

The full-scale monitoring results show that $\mathrm{PACl}$ added to the test clarifier achieved removals of $89 \pm 2 \%$ TSS, $76 \pm 4 \%$ tCOD, $58 \pm 7 \%$ sCOD, and $84 \pm 5 \%$ TP. On the other hand, the control primary clarifier, which is dosed with only ferric chloride, removed $77 \pm 5 \% \mathrm{TSS}, 62 \pm 12 \%$ tCOD, $35 \pm 10 \%$ sCOD, and $67 \pm 12 \%$ TP. A comparison of the two results between the full-scale test and control primary clarifiers reveal that the $\mathrm{PACl}$ combined with ferric chloride performed better than ferric chloride on its own, which is in agreement with the jar test results. Thus, it can be concluded that the $\mathrm{PACl}$ addition does greatly increase the performance of primary clarification. 
The improvements observed are not only limited to TSS removal, which in practice is the design parameter for most full-scale applications of CEPT for overflow conditions, but enhanced removals of COD, sCOD, and TP were also observed. The increased removal of these parameters will provide significant benefit through the redirection of additional carbon and phosphorus to primary sludge. The full-scale monitoring results presented in Figure 3 demonstrate that there is potential to optimize the CEPT process, providing a significant benefit for facilities looking to optimize phosphorus removal and increase carbon capture in primary sludge for redirection, reducing aeration requirements by limiting the carbon that must be oxidized through secondary treatment. As discussed previously, carbon redirection has the potential to significantly increase digester gas production rates for facilities equipped with anaerobic digesters. On the other hand, facilities that utilize incineration for solids disposal can derive benefit from increasing the calorific content of sludge processed, reducing supplemental fuel requirements or assisting in achieving autogenous sludge conditions. However, it is anticipated that the capture of additional nutrients in the primary sludge beyond those examined under the current study will occur, so additional study is required to assess the potential impacts of receiving sludge arising from $\mathrm{PACl}$ addition within anaerobic digestion systems.

\subsection{Influence of Influent Characteristics on Removal Rates}

The relationship between raw wastewater concentration (TSS, tCOD, sCOD, and TP) and corresponding removal rates for the test clarifier was plotted to determine if there was any correlation. To discern if the type of chemical dosing impacted the removal rate relative to influent characteristics, Figure $4 \mathrm{a}-\mathrm{d}$ were generated. The figures include data for Phases 1, 2, and 3 where Alcomer + ferric chloride, ferric chloride, and $\mathrm{PACl}+$ ferric chloride were added to the test clarifier, respectively.

From the plots of raw TSS concentration vs. the observed TSS removal rate (Figure 4a), there was no significant correlation observed under all test scenarios (Phases 1, 2, and 3). This result is consistent with past research by Exall and Marsalek [25], which reported that the performance of PACl on the removal of TSS does not depend on the initial TSS concentration.

For the relationship of $\mathrm{tCOD}, \mathrm{SCOD}$, and TP concentrations relative to their corresponding removal rates, an interesting phenomenon was found. It was observed that the removal rates of these parameters increased with the increase of the respective influent wastewater concentration, but only during Phase 1 when Alcomer was used. However, this relationship between removal rates and influent concentrations of tCOD, sCOD, and TP was not observed when PACl (Phase 3) was used as a polymer (Figure $4 \mathrm{~b}-\mathrm{d}$ ). This finding clearly demonstrates that COD and TP concentrations may influence their respective removal rates when Alcomer is dosed, but not PACl. This might be attributed to the difference in the removal mechanisms of the two polymers. The dominant removal mechanism for Alcomer is charge neutralization and that of $\mathrm{PACl}$ is both charge neutralization and polymer bridging. It should be noted that no dependency on influent characteristics for PACl could indicate that the polymer behaves similarly when applied to wastewater of varying characteristics, so the results observed under this study can be applicable to other sites. A comparative evaluation between the TP/TSS ratios as a parameter to evaluate the TP removal efficiency across all three phases was also conducted. As depicted in Figure 4e, for PACl addition (Phase 3), TP/TSS ratio and TP removal were negatively correlated $\left(r^{2}=0.92\right)$, and in the other two scenarios (Phases 1 and 2) TP removal was independent of the TP/TSS ratio $\left(r^{2}<0.10\right)$. Note that the $r^{2}$ was calculated after removing an outlier circled in red (Figure 4e). Therefore, at lower TSS concentrations, TP removal was adversely affected when PACl was added, which contradicts the findings of a study conducted by Szabo et al. [26], who observed less efficient phosphorus removal at higher TSS concentrations. 


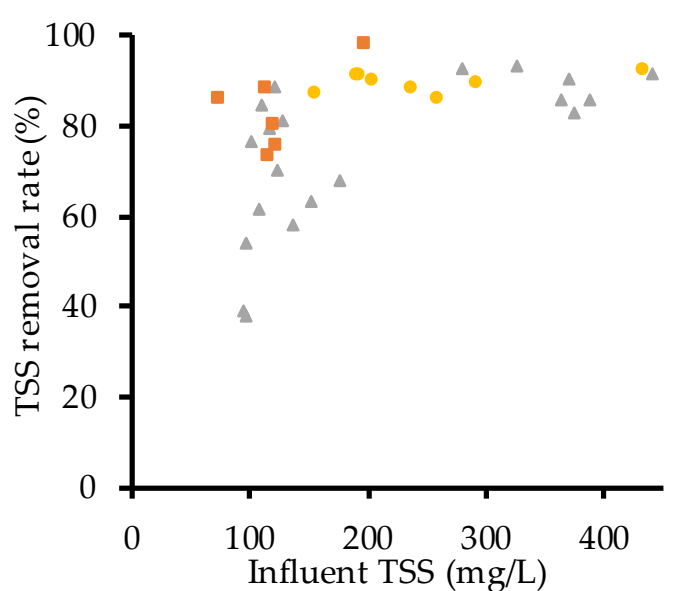

(a)

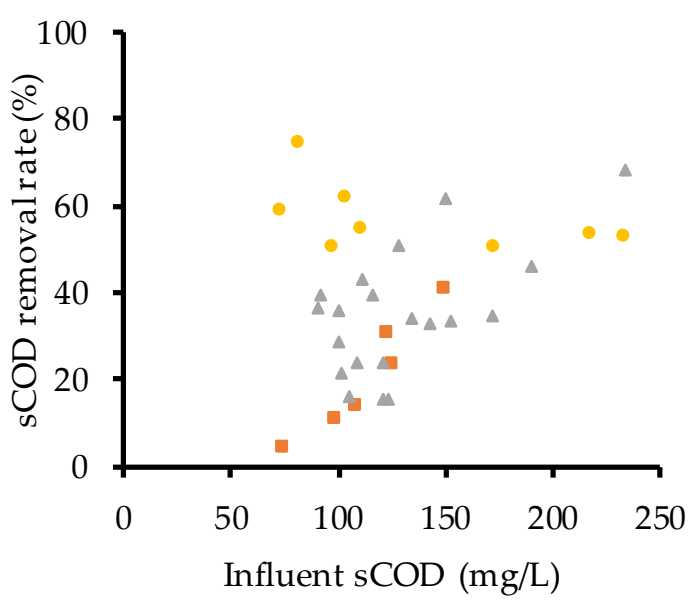

(c)

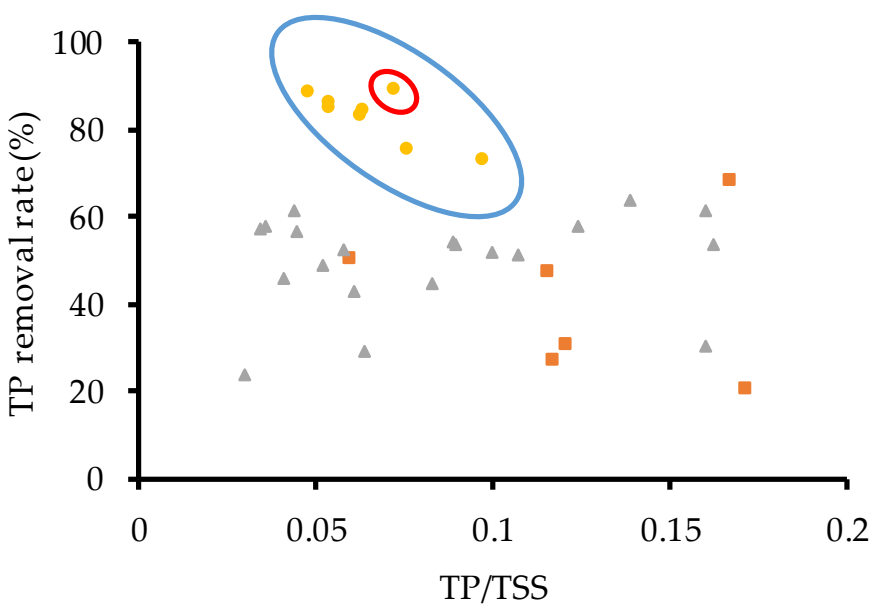

(e)

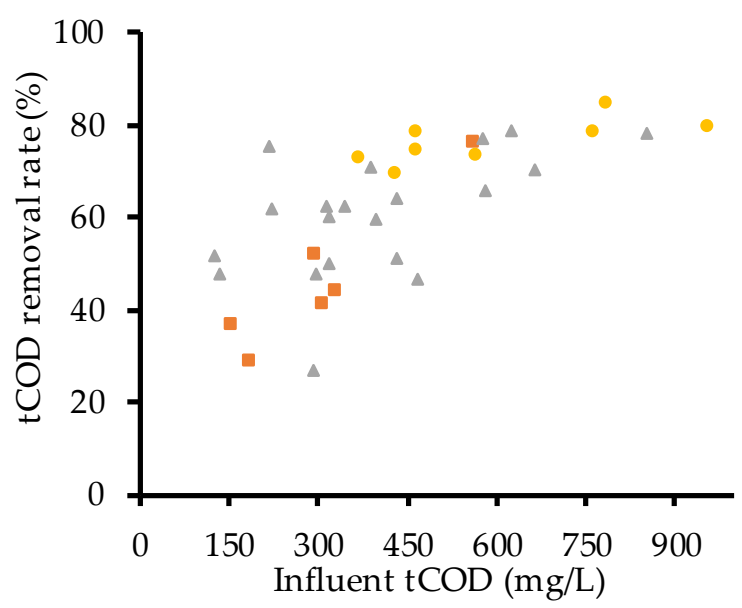

(b)

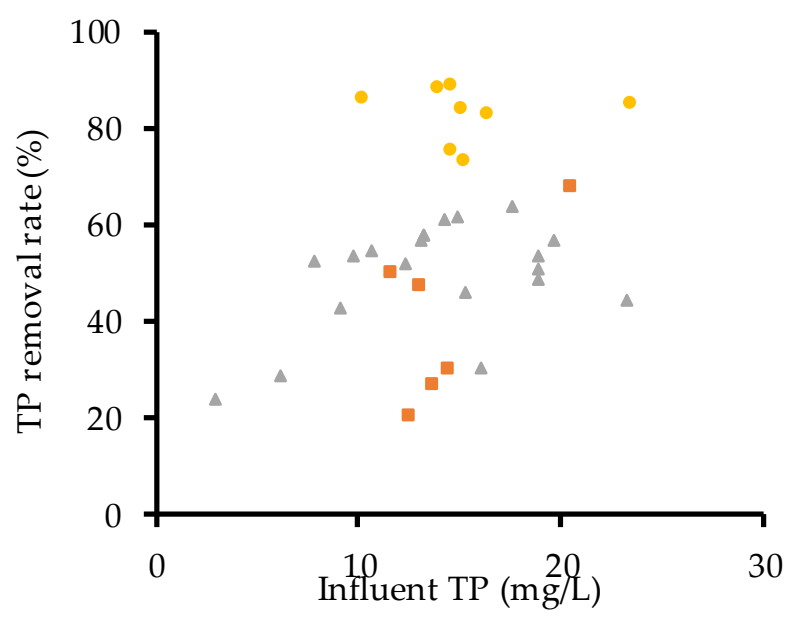

(d)

Figure 4. Effect of influent characteristics on removal rate: (a) the effect of TSS concentration, (b) the effect of total COD, (c) the effect of soluble COD, (d) the effect of TP concentration, and (e) the effect of $\mathrm{TP} / \mathrm{TSS}$ ratio.

\subsection{Influence of Influent Characteristics on Removal Rates during Summer versus Winter Season}

In this section, the impact of influent characteristics on removal rates were further characterized by comparing the summer versus winter data of the test clarifier during Alcomer polymer addition (Figure 5). The results were consistent with observations made in Section 3.4 except for sCOD 
removal where higher removals were observed during the summer season. For example, at a sCOD concentration of $100 \mathrm{mg} / \mathrm{L}$ the corresponding removal rate during winter was $10 \%$, whereas the removal increased to $30-50 \%$ during summer. This difference may be attributed to the presence of a larger colloidal fraction during summer. This also explained the discrepancy between the jar tests versus full-scale sCOD removal data for $\mathrm{PACl}$ where the jar test that was conducted during winter showed $20 \%$ removal, whereas an average removal of $60 \%$ was demonstrated during full-scale testing that was conducted during summer.

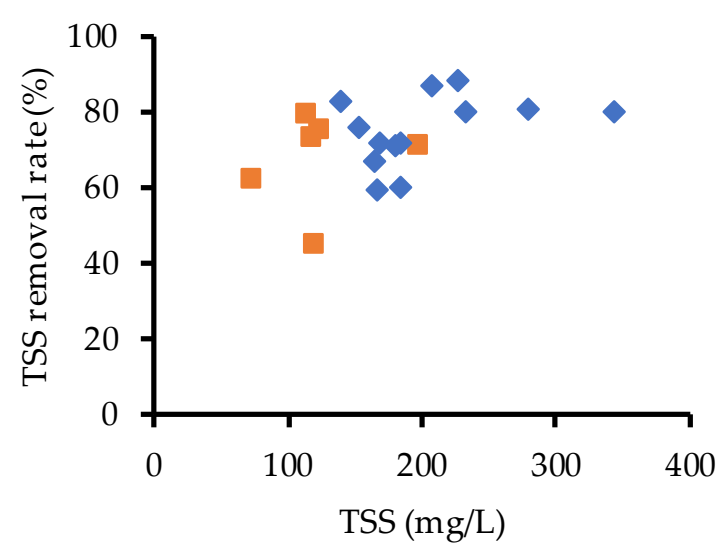

(a)

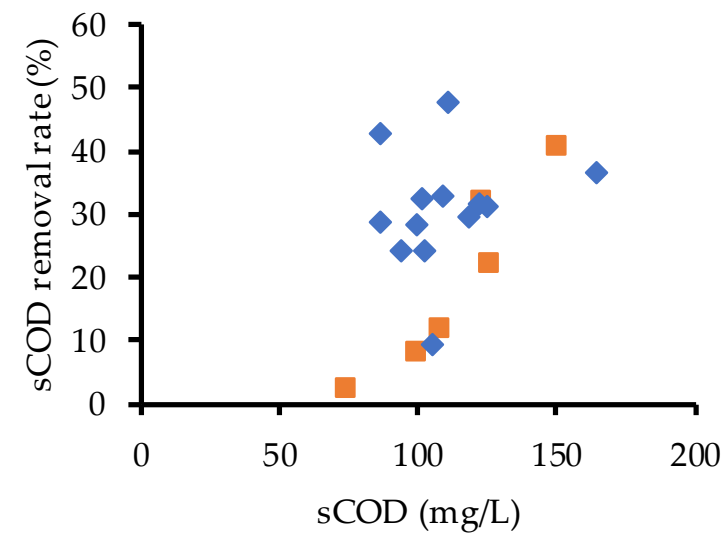

(c)

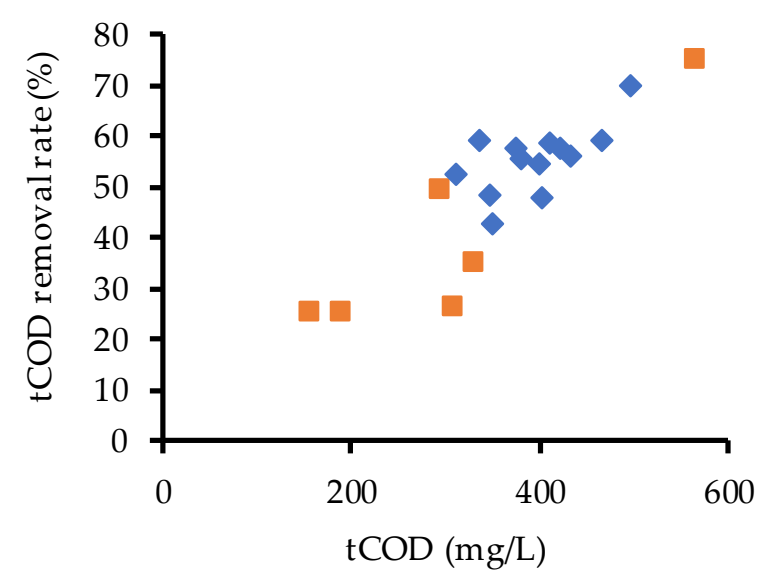

(b)

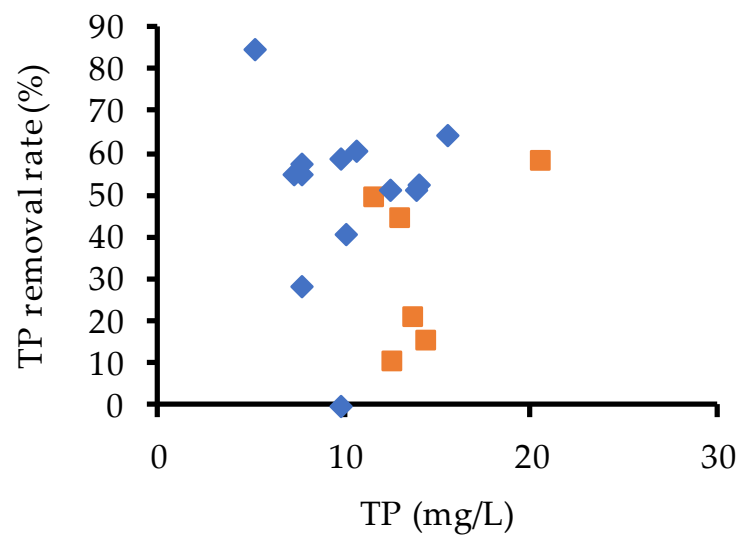

(d)

Winter $\diamond$ Summer

Figure 5. The effect of influent characteristics on removal rate during winter versus summer seasons: (a) TSS concentration, (b) total COD, (c) soluble COD, and (d) TP.

\section{Conclusions}

This study demonstrates that the optimized CEPT successfully achieved both carbon redirection and removal of phosphorus. Through jar testing, a dosage of $15 \mathrm{mg} / \mathrm{L}$ ferric chloride and $0.5 \mathrm{mg} / \mathrm{L}$ $\mathrm{PACl}$ was selected as the best coagulant and flocculant combination. The application of this optimum dosage in full-scale primary clarifier operation had demonstrated a removal efficiency of $76 \%$ tCOD, 58\% sCOD, $89 \%$ TSS, and $84 \%$ TP. The organic carbon transferred to CEPT sludge could increase anaerobic digester gas production or promote autogenous combustion in sludge incineration. Therefore, CEPT can be considered as a promising method to recover resources from wastewater. 
Supplementary Materials: The following is available online at http:/ / www.mdpi.com/2073-4441/11/3/547/s1. Figure S1: Seasonal changes in influent flow rate and temperature of Vauxhall WWTP.

Author Contributions: T.D., W.A.S., and M.D. conceived and designed the experiments; T.D. conducted the experiments; T.D. and W.A.S. analyzed the data and prepared the draft manuscript; M.D. reviewed, edited, and contributed to the final paper; K.M. provided wastewater treatment plant data and participated in the writing and editing.

Funding: This research was funded by the Natural Sciences and Engineering Research of Canada (NSERC), grant number 2017-05178.

Acknowledgments: We thank Geordie Gauld and Randy Robinson from the City of London for their assistance in wastewater sample and data collection.

Conflicts of Interest: The authors declare no conflict of interest.

\section{References}

1. Jimenez, J.A. Carbon redirection in water reuse and recovery facilities: Technologies Overview. Proc. Water Environ. Fed. 2017, 3, 21-23. [CrossRef]

2. Neupane, D.R.; Riffat, R.; Murthy, S.N.; Peric, M.R.; Wilson, T.E. Influence of Source Characteristics, Chemicals, and Flocculation on Chemically Enhanced Primary Treatment. Water Environ. Res. 2008, 80, 331-338. [CrossRef] [PubMed]

3. Tchobanoglous, G.; Stensel, H.D.; Tsuchihashi, R.; Burton, F.L. Wastewater Engineering: Treatment and Resource Recovery, 5th ed.; McGraw-Hill Education: New York, NY, USA, 2014.

4. Wang, H.; Li, F.; Keller, A.A.; Xu, R. Chemically enhanced primary treatment (CEPT) for removal of carbon and nutrients from municipal wastewater treatment plants: A case study of Shanghai. Water Sci. Technol. 2009, 60, 1803-1809. [CrossRef]

5. Ødegaard, H. Optimized particle separation in the primary step of wastewater treatment. Water Sci. Technol. 1998, 37, 43-53. [CrossRef]

6. Aiyuk, S.; Amoako, J.; Raskin, L.; Van Haandel, A.; Verstraete, W. Removal of carbon and nutrients from domestic wastewater using a low investment, integrated treatment concept. Water Res. 2004, 25, 1321-1330. [CrossRef] [PubMed]

7. He, Q.; Wang, H.; Xu, C.; Zhang, J.; Zhang, W.; Zou, Z.; Yang, K. Feasibility and optimization of wastewater treatment by chemically enhanced primary treatment (CEPT): A case study of Huangshi. Chem. Spec. 2016, 28, 209-215. [CrossRef]

8. Ghafari, S.; Aziz, H.A.; Isa, M.H.; Zinatizadeh, A.A. Application of response surface methodology (RSM) to optimize coagulation-flocculation treatment of leachate using poly-aluminum chloride (PAC) and alum. J. Hazard. Mater. 2009, 163, 650-656. [CrossRef] [PubMed]

9. National Research Council. Wastewater Management in Urban Coastal Areas; National Academy Press: Washington, DC, USA, 1992.

10. Lin, L.; Li, R.H.; Li, Y.; Xu, J.; Li, X. Recovery of organic carbon and phosphorus from wastewater by Fe-enhanced primary sedimentation and sludge fermentation. Process Biochem. 2017, 54, 135-139. [CrossRef]

11. Mahmoud, E.K. Chemically enhanced primary treatment of textile industrial effluents. Polish J. Environ. Stud. 2009, 18, 651-655.

12. Shi, B.; Li, G.; Wang, D.; Feng, C.; Tang, H. Removal of direct dyes by coagulation: The performance of preformed polymeric aluminum species. J. Hazard. Mater. 2007, 143, 567-574. [CrossRef]

13. Vauxhall Wastewater Treatment Plant: 2016 Annual Report. Available online: http://www.london.ca/ residents/Sewers-Flooding/Sewage-Treatment/Documents/VAUXHALL16-AODA.pdf (accessed on 9 November 2017).

14. Aguilar, M.I.; Sáez, J.; Lloréns, M.; Soler, A.; Ortuño, J.F.; Meseguer, V.; Fuentes, A. Improvement of coagulation-flocculation process using anionic polyacrylamide as coagulant aid. Chemosphere 2005, 58, 47-56. [CrossRef] [PubMed]

15. De Feo, G.; De Gisi, S.; Galasso, M. Definition of a practical multi-criteria procedure for selecting the best coagulant in a chemically assisted primary sedimentation process for the treatment of urban wastewater. Desalination 2008, 230, 229-238. [CrossRef] 
16. APHA; AWWA; WPCF. Standard Methods for the Examination of Water and Wastewater, 21st ed.; American Public Health Association: Washington, DC, USA, 2005.

17. Ghasemi, A.; Zahediasl, S. Normality tests for statistical analysis: A guide for non-statisticians. Int. J. Endocrinol. Metab. 2012, 10, 486-489. [CrossRef] [PubMed]

18. Lin, L.; Li, R.H.; Li, X.Y. Recovery of organic resources from sewage sludge of Al-enhanced primary sedimentation by alkali pretreatment and acidogenic fermentation. J. Clean. Prod. 2018, 172, 3334-3341. [CrossRef]

19. Edzwald, J.K. Coagulation in drinking water treatment: Particles, organics and coagulants. Water Sci. Technol. 1993, 27, 21-35. [CrossRef]

20. Haydar, S.; Aziz, J.A. Characterization and treatability studies of tannery wastewater using chemically enhanced primary treatment (CEPT)-A case study of Saddiq Leather Works. J. Hazard. Mater. 2009, 163, 1076-1083. [CrossRef]

21. Hauduc, H.; Takács, I.; Smith, S.; Szabo, A.; Murthy, S.; Daigger, G.T.; Spérandio, M. A dynamic physicochemical model for chemical phosphorus removal. Water Res. 2015, 73, 157-170. [CrossRef]

22. Ratnaweera, H.; Odegaard, H.; Fettig, J. Coagulation with prepolymerized aluminium salts and their influence on particle and phosphate removal. Water Sci. Technol. 1992, 26, 1229-1237. [CrossRef]

23. Wei, J.; Gao, B.; Yue, Q.; Wang, Y.; Li, W.; Zhu, X. Comparison of coagulation behavior and floc structure characteristic of different polyferric-cationic polymer dual-coagulants in humic acid solution. Water Res. 2009, 43, 724-732. [CrossRef]

24. Yan, M.; Wang, D.; Ni, J.; Qu, J.; Ni, W.; Van Leeuwen, J. Natural organic matter (NOM) removal in a typical North-China water plant by enhanced coagulation: Targets and techniques. Sep. Purif. Technol. 2009, 68, 320-327. [CrossRef]

25. Exall, K.; Marsalek, J. A coagulant survey for chemically enhanced primary treatment of synthetic CSOs. Water. Air. Soil Pollut. 2013, 224, 1414. [CrossRef]

26. Szabó, A.; Takács, I.; Murthy, S.; Daigger, G.T.; Licskó, I.; Smith, S. Significance of Design and Operational Variables in Chemical Phosphorus Removal. Water Environ. Res. 2008, 80, 407-416. [CrossRef] [PubMed]

(C) 2019 by the authors. Licensee MDPI, Basel, Switzerland. This article is an open access article distributed under the terms and conditions of the Creative Commons Attribution (CC BY) license (http:/ / creativecommons.org/licenses/by/4.0/). 